\title{
Partition-Variant Desferrithiocin Analogues: Organ Targeting and Increased Iron Clearance
}

\author{
Raymond J. Bergeron, * Jan Wiegand, James S. McManis, William R. Weimar, § Jeong-Hyun \\ Park, Eileen Eiler-McManis, Jennifer Bergeron, $\dagger$ and Gary M. Brittenham $\mathbb{I}$
}

Departments of Medicinal Chemistry and Educational Psychology, University of Florida, Gainesville, FL 32610-0485 and Departments of Pediatrics and Medicine, Columbia University College of Physicians and Surgeons, New York, New York 10032

\section{SUPPORTING INFORMATION}

Elemental analytical data for synthesized compounds 6, 8, and $\mathbf{1 0 .}$ 


\section{Elemental Analyses}

\begin{tabular}{c|cccccc}
\hline Cmpd no. & C calcd & C found & H calcd & H found & N calcd & N found \\
\hline $\mathbf{6}$ & 52.16 & 51.77 & 4.38 & 4.18 & 5.53 & 5.34 \\
$\mathbf{8}$ & 53.92 & 53.89 & 4.90 & 4.88 & 5.24 & 5.11 \\
$\mathbf{1 0}$ & 62.22 & 62.00 & 3.73 & 3.93 & 10.37 & 10.30 \\
\hline
\end{tabular}

